\title{
Potential detection of illegal fishing by passive acoustic telemetry
}

\author{
David M. Tickler ${ }^{1 *}$, Aaron B. Carlisle², Taylor K. Chapple ${ }^{3}$, David J. Curnick ${ }^{4}$, Jonathan J. Dale ${ }^{3}$, Robert J. Schallert ${ }^{3}$ \\ and Barbara A. Block ${ }^{3}$
}

\begin{abstract}
Acoustic tagging is typically used to gather data on the spatial ecology of diverse marine taxa, informing questions about spatio-temporal attributes such as residency and home range, but detection data may also reveal unanticipated insights. Many species demonstrate predictable site fidelity, and so a sudden cessation of detections for multiple individuals may be evidence of an atypical event. During 2013 and 2014, we acoustically tagged 47 grey reef sharks (Carcharhinus amblyrhynchos) and 48 silvertip sharks (Carcharhinus albimarginatus) near reefs in the British Indian Ocean Territory (BIOT) Marine Protected Area (MPA). From March 2013 to November 2014 inclusive, tags were 'lost', i.e. permanently ceased to be detected within the monitoring area, at an average rate of $2.6 \pm 1.0$ tags per month. Between 1 and 10 December 2014, detection data suggest the near-simultaneous loss of 15 of the remaining 43 active tagged sharks, a monthly loss rate over five times higher than during the previous 21 months. Between 4 and 14 December of 2014, the BIOT patrol vessel encountered 17 vessels engaged in suspected illegal fishing in the northern BIOT MPA; such sightings averaged one per month during the previous 8 months. Two of these vessels were arrested with a total of 359 sharks on board, of which grey reef and silvertip sharks constituted $47 \%$ by number. The unusual and coincident peaks in tag loss and vessel sightings, and the catch composition of the arrested vessels, suggest illegal fishing as a plausible explanation for the unusual pattern in our detection data. A Cox proportional hazards model found that the presence of fishing vessels increased the risk of tag loss by a factor of $6.0(95 \% \mathrm{Cl} 2.6-14.0$, $p<0.001)$. Based on the number of vessels sighted and the average number of sharks on vessels arrested in BIOT during 2014, we conservatively estimate that over 2000 sharks may have been removed during the suspected fishing event. Based on average catch compositions, over 1000 would have been grey reef and silvertip sharks. Assuming a closed population mark-recapture model, over one-third of the locally resident reef sharks may have been removed from the monitoring area. The data suggest that even sporadic fishing events may have a marked impact on local reef shark populations, but also demonstrate the potential of electronic tagging a tool for detecting illegal or otherwise unreported fishing activity.
\end{abstract}

Keywords: Acoustic telemetry, Illegal fishing, Reef sharks, MPA, Monitoring

\section{Background}

Acoustic telemetry, and electronic tagging in general, is an increasingly popular method of gathering data on the spatial ecology of diverse marine taxa [1-5]. Acoustic tags produce data when tagged animals are in range of a receiving unit that records the tag's unique code plus a

\footnotetext{
*Correspondence: davetickler@gmail.com

${ }^{1}$ Oceans Institute: Centre for Marine Futures, University of Western

Australia, 35 Stirling Highway, Crawley, Perth, WA 6009, Australia

Full list of author information is available at the end of the article
}

time stamp, as well as sensor data, such as depth $[1,2]$, temperature [3, 4] and acceleration [5], if available [6]. Data are typically interpreted in terms of residency patterns within a network of receiver elements, with gaps in detection assumed to be absences from the area. Gaps in detection may occur for multiple reasons, which may be classified as true and false absences. True absences occur when an animal (or, more accurately, a tag) leaves the monitored area (determined by the number and location of receivers, and their detection range). This may occur for multiple reasons, including mortality/predation $[7,8]$, 
migration [9-11] and tag shedding or expulsion [12, 13]. False absences occur when an animal is present within the area being monitored but remains undetected. This typically occurs due to decreases in receiver detection efficiency with environmental conditions, tag or battery failure, interference with tag signals arising from biogenic noise or other tags, or a tag simply failing to transmit while the animal is in range of a receiver, due to the length of the programmed transmission interval [14].

Acoustic telemetry is frequently employed to study reef shark movements and behaviour, due to the potentially important role they play in reef ecosystem connectivity and health and the growing emphasis on conserving coral reef ecosystems worldwide [15-18]. Reef sharks generally exhibit high degrees of fidelity to tagging sites or reefs and remain within the range of detection arrays for long periods [19-21]. While reef sharks have been shown to make regular journeys between adjacent reefs in coastal waters [22], these occurred over distances of $10-30 \mathrm{~km}$, in water shallower than $100 \mathrm{~m}$. Conversely, long-distance movements across deep waters off the continental shelf appear rare, although data from both acoustic and satellite archival tags indicate that pelagic movements by reef sharks do occur $[19,23]$. These behavioural characteristics suggest that the simultaneous cessation of detections from a group of tagged animals may indicate a significant atypical event, such as a mass change in behaviour or mortality.

The growing demand for marine protein and ongoing demand for shark fins have increasingly made reef sharks the target of commercial as well as traditional subsistence fisheries [24, 25]. Consequently, reef-based fishing for these species by both legal and illegal fishing operations is widespread and is thought to have driven sharp declines in abundance in affected areas [26, 27]. Marine protected areas and shark sanctuaries have been declared around the world to attempt to relieve the fishing pressure on sharks, but deterring illegal fishing remains challenging given the paucity of alternatives for many fishers, the incentive provided by the relatively lucrative fin trade, and the logistics of enforcement [28, 29]. Where shark populations are monitored using acoustic telemetry it is therefore possible that fishing may lead to the permanent removal of a tag from the monitoring area (hereafter 'tag loss'), even when the study site is officially closed to fishing. Predatory fishes such as sharks are typically targeted using longlines consisting of thousands of baited hooks. Fishing mortality amongst a population of tagged sharks could therefore be hypothesised to present as the nearsimultaneous loss of detection of multiple tagged animals within a short time frame.

We present a case study from an ongoing acoustic monitoring project in the British Indian Ocean Territory
(BIOT) Marine Protected Area (MPA). We examine patterns in the temporal clustering of tag loss events (i.e. the last date of detection for tags within the study) alongside data on reported sightings or arrests of suspected illegal fishing vessels, to see if there is a threshold of tag loss that might be considered unusual, and whether this correlates with fishing or natural drivers such as weather. We further use the catch data from arrested vessels to generate estimates of the potential impact on the local shark population by such fishing events.

\section{Results}

The number of sharks being detected within the receiver array declined over time, following each tagging field trip. This loss rate averaged $4.1 \pm 1.4$ tags per month during 2013, but reduced to $1.3 \pm 0.9$ tags per month during 2014 (Fig. 1). The combined average loss rate for this period was $2.6 \pm 1.0$ tags per month $(\mathrm{SD}=2.3$ tags per month). Reduced average loss/failure rate in 2014 was likely a result of using surgical implantation of tags, whereas tags were attached externally in 2013. Following the April 2014 tagging trip, 43 animals (15 grey reef sharks and 28 silvertip sharks) were considered active within the study area (Fig. 1). Detection activity varied amongst individual sharks, with mean detection rate ranging from 1.5 to 30 days per month, but showed no obvious temporal patterns (Fig. 2).

From 1 December to 10 December 2014, 15 previously active sharks ( 2 grey reef sharks and 13 silvertip sharks) ceased to be detected and had not been redetected as of March 2018 (Figs. 1, 2). Fork lengths were 94 and $123 \mathrm{~cm}$ for the two grey reef sharks and ranged from 81 to $180 \mathrm{~cm}$ for silvertip sharks. There were 8 females and 6 males amongst the 14 animals for which sex data were recorded (Table 1, Additional file 1: Table S1). These animals had all been detected consistently since tagging, with a mean interval between consecutive detections of $2.1 \pm 0.1 \mathrm{~h}$ and a maximum absence of 37.5 days (900 h) (Fig. 2). The remaining tags showed no change in detection activity during and after the December $1-10$ period (Fig. 2), and detection of sharks continued at the locations assumed to have been affected by fishing (Additional file 1: Fig. S1).

The BIOT Patrol Vessel (BPV) reported encountering a total of 17 suspected illegal fishing vessels on the 4,11 and 14 December 2014 (2, 7 and 8 vessels per day, respectively) in locations surrounding the monitored area [30]. The majority of the Indian-flagged vessels were encountered in the known anchorage in the northwest corner of Blenheim Reef (Fig. 3). The BPV had reported sighting an average of one vessel per month in the previous 8 months (Fig. 4). Comparing monthly tag losses and vessel sightings from March to December 2014 revealed similar 


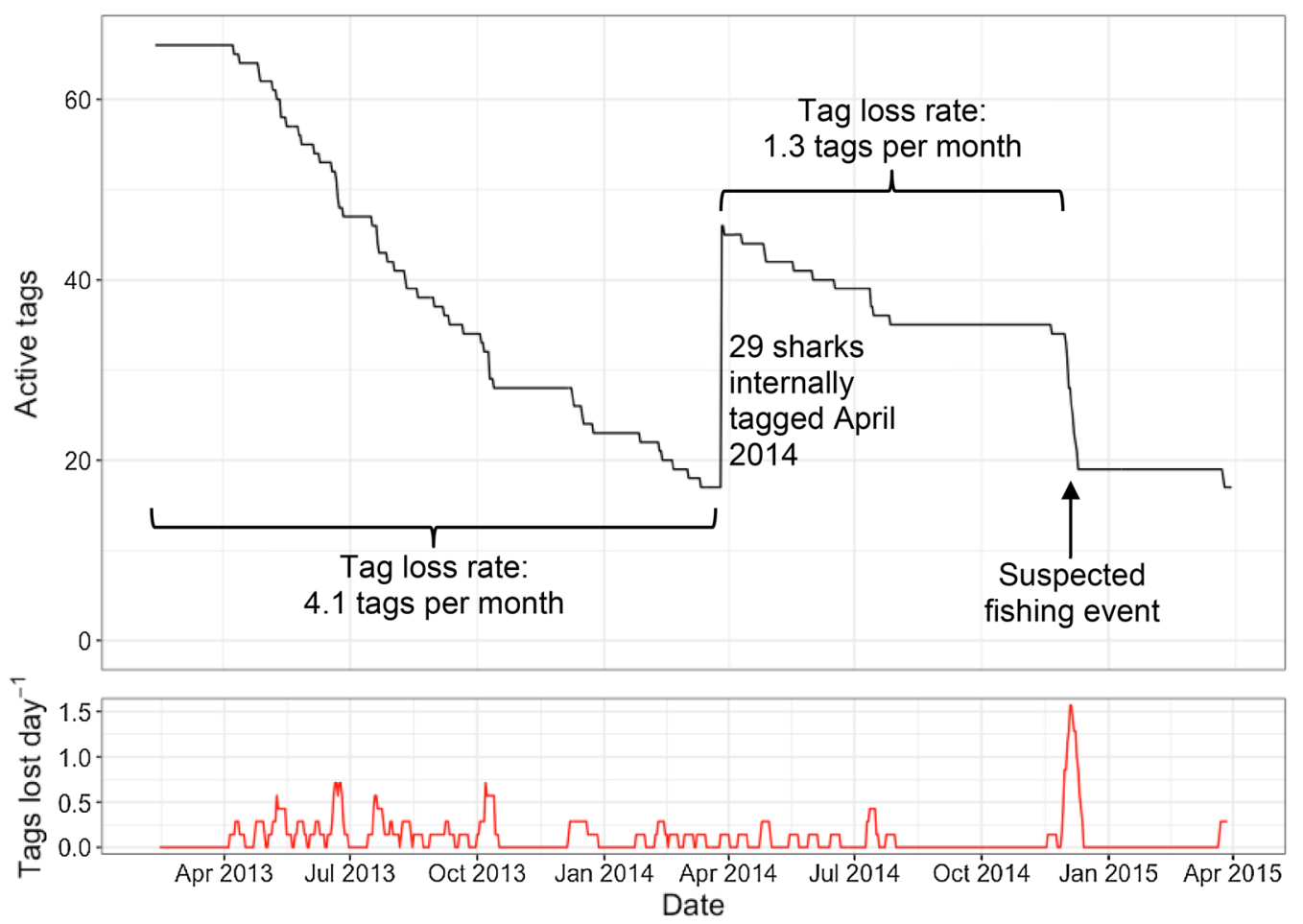

Fig. 1 Trend in active reef shark tags by the acoustic monitoring network in the BIOT MPA over 2 years, March 2013-April 2015

patterns, with the peak level of fishing vessel sightings in December corresponding with the highest loss in tag detections (Fig. 4). Cox proportional hazards analysis found that the hazard ratio for tag loss associated with fishing events was 6.0 (95\% CI 2.6-14.0, $p<0.001$, Fig. 5, Table 2). Kaplan-Meier curves suggest the presence of fishing reduced tag survival time by over $50 \%$ (zero probability of survival by 631 days, Additional file 1: Fig. S2). The fishing event coincided with a period of calm weather in northern part of BIOT, with mean wind speeds of $4.5 \mathrm{~ms}^{-1}$ (8.7 kts) and wave heights of $1.3 \mathrm{~m}$ during the first half of December (Additional file 1: Fig. S3).

Of the 17 vessels detected in December 2014, two vessels were detained with an average of 180 sharks each on board. One vessel had 308 sharks on board, including 98 silvertip and 60 grey reef sharks; the other had 51 sharks on board, including 28 silvertip and 4 grey reef sharks (Table 3) [30]. Catch data from reports for all arrests made in the BIOT MPA during 2014 gave a lower mean catch size of $135 \pm 57$ sharks per vessel, of which $9.8 \%$ were grey reef sharks and $37.6 \%$ were silvertip sharks (Additional file 1: Table S2) [30]. If we assume these numbers are representative of a typical fishing catch within BIOT, then extrapolating from the observed data, the 17 vessels sighted in December 2014 could have collectively yielded an potential total catch of $>2000$ sharks of which $>200$ would have been grey reef sharks and nearly 900 would have been silvertip sharks. Based on the assumption that these fishing vessels removed 15 of 43 tagged sharks considered to remain at large at the time, an abundance index, assuming equal catchability and a closed system, would imply that nearly one-third of the local shark population was removed.

\section{Discussion}

Acoustic telemetry provides data about tagged animals within a detection area surrounding a receiver that is determined empirically within a location but usually is less than $500 \mathrm{~m}$ in radius [6]. Thus, acoustic tagging does not produce information about animals outside the detection range of receivers, and so, in most cases, nothing can be known for certain about why tagged animals ceased being detected. However, reef sharks have been observed to exhibit high degrees of site fidelity, remaining at home reefs or within groups of adjacent reefs for months at a time with few, brief absences [22, 31, 32]. Residency is thought to be higher to reefs that are geographically isolated, as in the case of BIOT, although limited instances of connectivity between groups of reefs separated by distances of tens, rather than hundreds, of kilometres have been shown on the GBR, Hawaii and Palmyra [22, 23, 33]. Where animals have been observed 


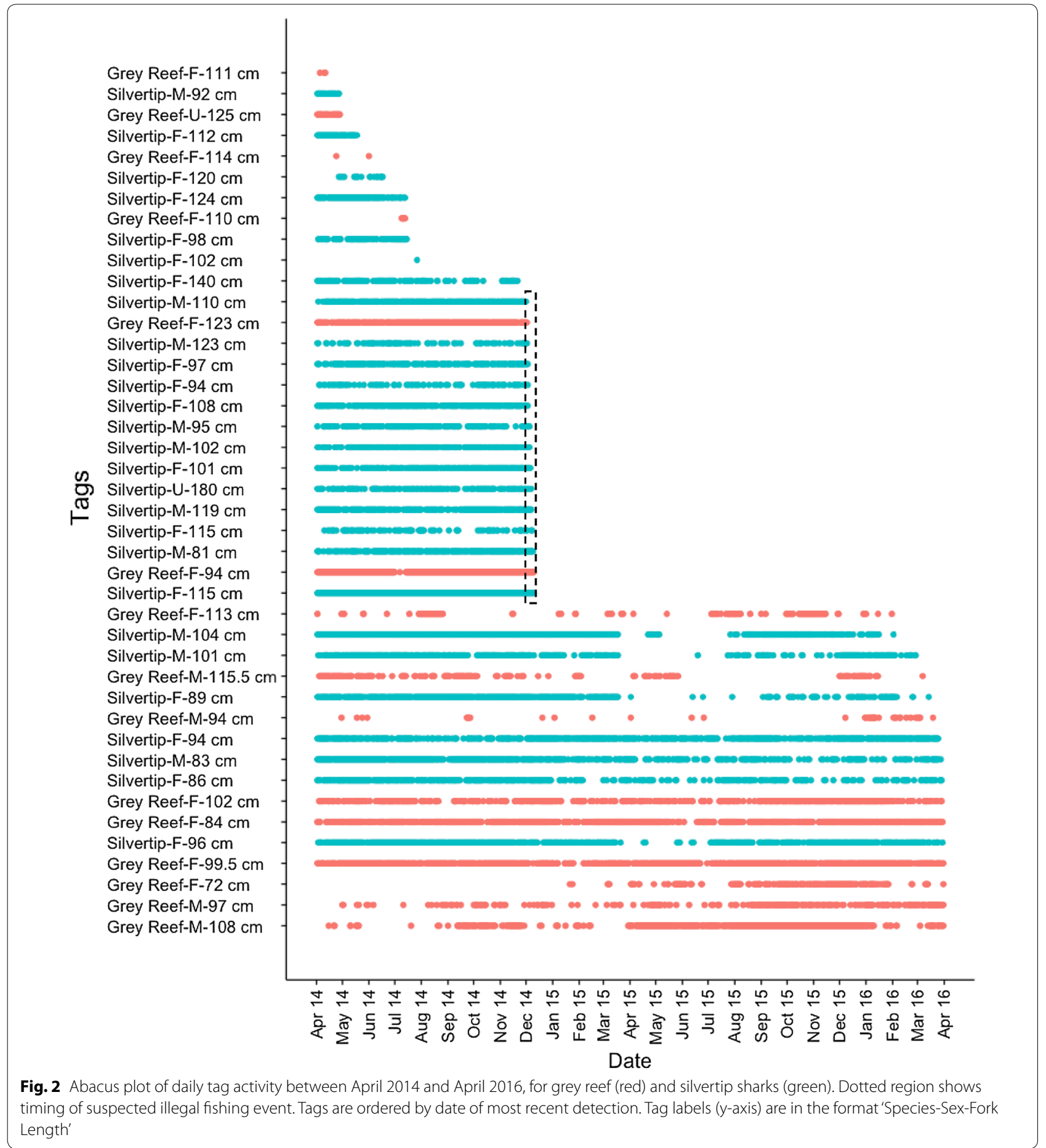

Table 1 Demographic data on sharks lost in December 2014

\begin{tabular}{|c|c|c|c|c|c|c|c|c|}
\hline \multirow[t]{2}{*}{ Species } & \multirow[b]{2}{*}{$\#$} & \multicolumn{3}{|c|}{ Sex } & \multicolumn{4}{|c|}{ Fork length (cm) } \\
\hline & & $M$ & $F$ & $U$ & Mean & $\mathrm{Cl}$ & Min & Max \\
\hline Grey reef & 2 & & 2 & & 106.0 & 19.8 & 94 & 123 \\
\hline Silvertip & 13 & 6 & 6 & 1 & 114.4 & 7.0 & 81 & 180 \\
\hline
\end{tabular}


to exhibit mass movements there has typically been a clear driver-a change in environmental conditions [34], reproduction [10], migratory stage, or the arrival of a predator at the study site [35] — and animals were often detected subsequent to the event.

In this study, we describe a sudden drop in activity amongst the acoustically tagged sharks in a study site and hypothesise that a sudden increase in the rate of tag loss may represent a 'fishing signature' that corresponds to the illegal fishing activity in the area at the same time. This is supported by the concordance between levels of tag loss and apparent fishing activity throughout the rest of the 2014 monitoring period, and survival analysis which found that the presence of fishing vessels was associated with shorter survival times and a sixfold higher risk of 'mortality' based on Kaplan-Meier curves and Cox proportional hazard modelling, respectively. Given the difficulty in detecting illegal fishing in a remote area the size of the BIOT MPA, it is possible that the sightings data do not accurately reflect true levels of fishing activity. However, assuming consistent patrolling effort in each month, levels of sightings/arrests are assumed to be proportional to fishing effort; Price et al. [36] assumed that sightings represented $10 \%$ of total incursions by illegal fishing vessels. Acoustic tagging may therefore be able to provide data from which to deduce enforcement efficiency by recording undetected IUU events. Tag loss during the month of our assumed fishing event was over three standard deviations above the average for the preceding 21 months of monitoring, suggesting an extreme event. Once a baseline for 'natural' tag loss from an acoustic array is established, monthly spikes in tag loss might be used to infer an undetected fishing incursion.

Alternative explanations for the observed loss of tags must be considered, including mass movements linked to age and sex, predation, and equipment failure. However, given the scale of the tag loss, credible alternatives to the hypothesis of removal by fishing seem unlikely. Female grey reef sharks on the Great Barrier Reef have been observed to leave home reef sites at certain times of year, which is assumed to correspond to parturition amongst pregnant individuals [10]. Similarly, site fidelity has been shown to vary ontogenetically with younger individuals less site attached than larger, older sharks of the same species [10]. However, our data show a simultaneous change in behaviour of a group of animals of mixed species, sex and sizes from multiple sites across the monitored reefs (Figs. 2, 4, Additional file 1: Table S1). A second potential driver could be local or atoll-wide environmental conditions driving a mass exodus of sharks. However, detection patterns amongst the remaining tagged animals were unchanged through the period in question (Fig. 2). Smaller reef sharks are known to be preyed on by larger species such as hammerheads [37,38], and predation of silvertip sharks in BIOT is suspected based on archival tag data (unpublished data). Natural predation cannot therefore be discounted as being responsible for at least some of the 'lost' tags. However, we consider it unlikely to account for such a concentration of incidents. Finally, it is possible that the loss of tags reflected equipment failure, either of tags or receivers, but again this is unlikely. The tags had been operating for between 19 and 34\% of their nominal battery life, were from different production batches, and had been performing consistently well since deployment (Fig. 3, Additional file 1: Table S1). The receiver network was clearly working properly, as the remaining tags continued to be detected. The pattern of indiscriminate loss of sharks of mixed species, sex and age from multiple sites over a short period could, however, be explained by fishing activity by a group of vessels moving through the atolls during that period. This hypothesis is also supported by the fact that silvertip sharks formed the majority of both the sharks observed in vessel catches and of the tags that had disappeared. We note that our sharks also fall well within the size distribution of animals taken by illegal fishing vessels in previous years (Additional file 1: Fig. S4) [39], confirming that these vessel target size classes overlapping our tagged cohort. Finally, a tag deployed during the most recent tagging field work in BIOT, in April 2018, was returned from a fishing market in Sri Lanka (BB, pers. comm.) confirming the interaction between illegal fisheries and animals in our tagging programme.

Illegal fisheries targeting sharks have been implicated in the reductions in reef shark numbers in the BIOT MPA during the 1980s, prior to protection, as reported by Graham et al. [40]. Illegal vessel sightings have since continued to be reported by the BIOT MPA authorities and anecdotal evidence from vessel sightings and discarded longlines on reefs during scientific expeditions suggest that the problem is ongoing. The pattern of vessel sightings reported by the BIOT patrol vessel suggests that fishing activity is sporadic with occasional pulses of activity, perhaps in response to market demand, fuel prices or weather conditions. The December 2014 vessel sightings corresponded with a drop in mean wind speed and wave

(See figure on next page.)

Fig. 3 Map of the BIOT MPA showing location of receiver array (yellow squares), dates and locations of encounters with illegal fishing vessels (triangles), and the last detection locations of 15 sharks in December 2014 (blue circles). Inset shows boundary of the BIOT MPA (dashed line) and its location in the Indian Ocean 


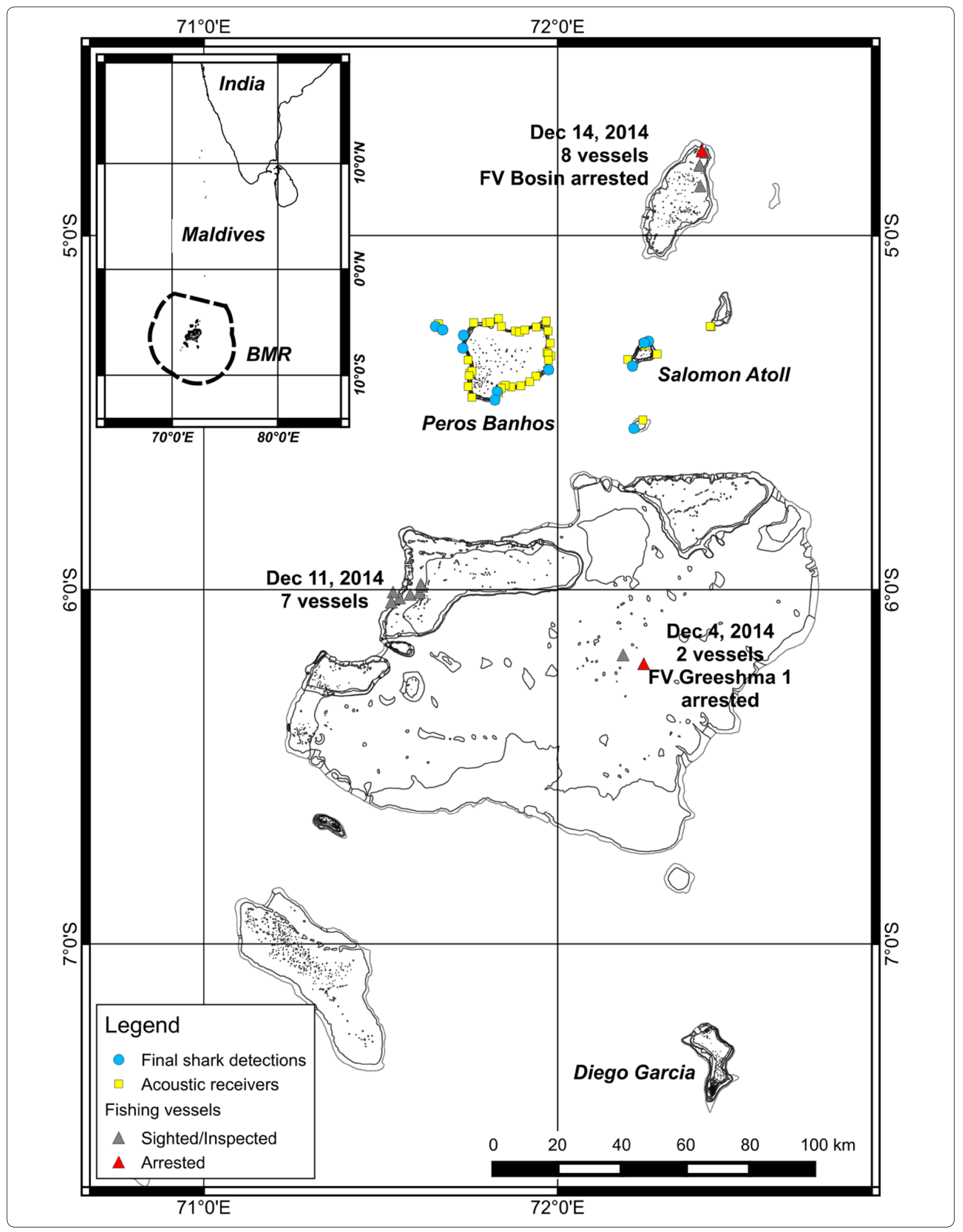




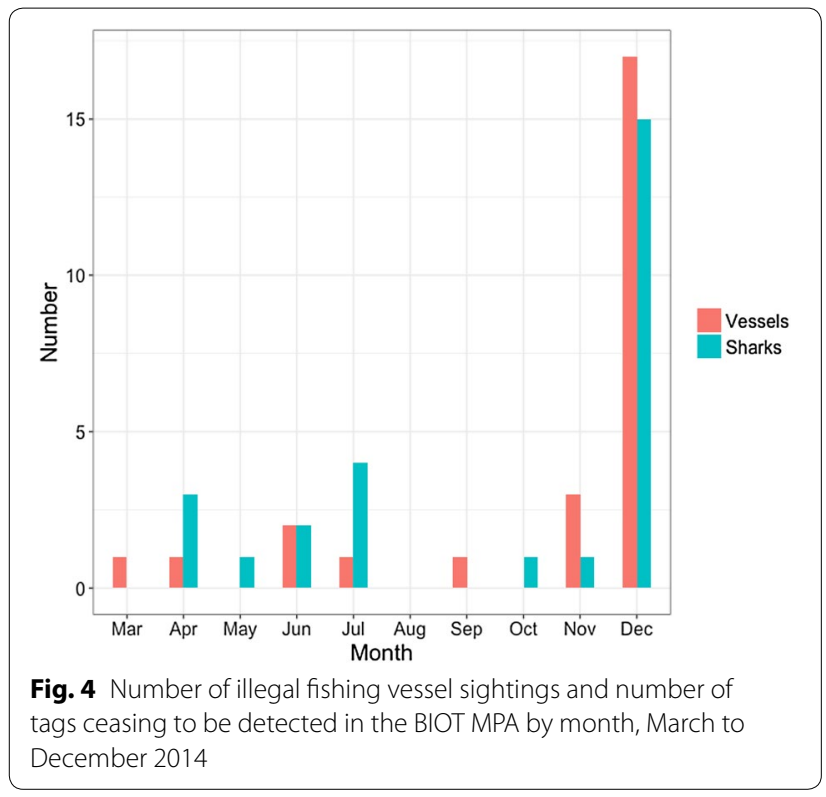

height in the local area, presumably creating favourable conditions for fishing (Additional file 1: Fig. S3a,b). Calm weather and surface conditions may also have favoured the vessels transiting into and out of BIOT from their home ports in India and Sri Lanka. Late 2014 also saw a $25 \%$ fall in the price of marine diesel oil relative to the middle of the year (http://www.bunkerindex.com, Additional file 1: Fig. S3c) which would have lowered the costs of a relatively long transit to the BIOT fishing grounds. There may be other underlying macroeconomic and political drivers affecting levels of illegal fishing in BIOT. The majority of the vessels sighted in December 2014 came from Tamil Nadu in south western India, where since 2013 the government has been offering increasing subsidies to convert trawlers to tuna longliners, in order to reduce fishing pressure and conflict in waters shared with neighbouring Sri Lanka (http://www.fisheries. tn.gov.in/pdf/Tuna_guidelinesGO.pdf). Starting at 25\%, this subsidy has now been increased to $70 \%$ of the vessel

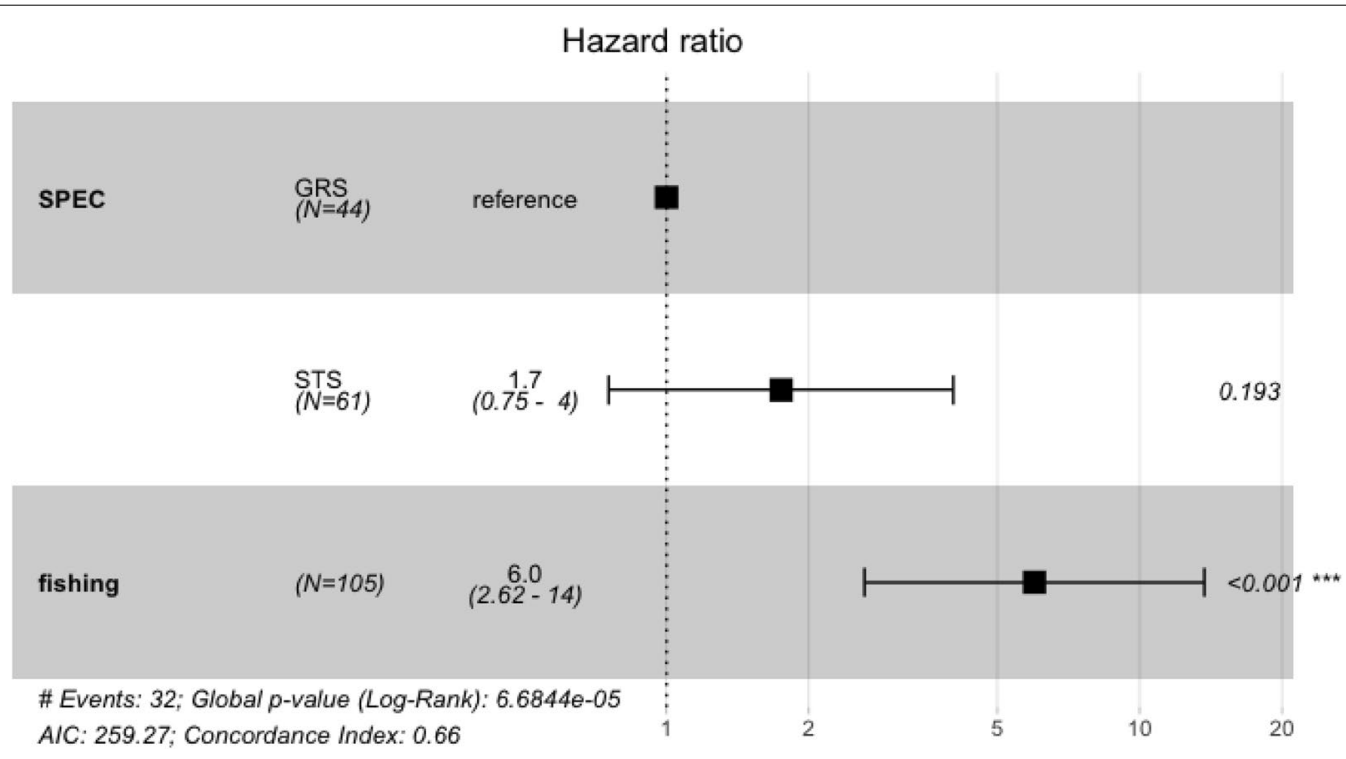

Fig. 5 Forest plot of Cox proportional hazards model for tag loss with shark species and presence of fishing at time of last detection as covariates. Error bars show 95\% confidence interval of hazard ratio. Hazard ratios greater than 1 indicate increased risk of tag loss

Table 2 Parameters of Cox proportional hazard model

\begin{tabular}{lllllrrrr}
\hline Term & Coefficient & SE & $\begin{array}{l}\text { Hazard ratio (HR: } \\
\boldsymbol{e}^{\text {coef }}\end{array}$ & $\boldsymbol{Z}$ score & $\boldsymbol{p}$ value & HR Cl lower & HR Cl upper \\
\hline species:STS & 0.56 & 0.43 & 1.8 & 1.30 & 0.193 & 0.76 & 4.0 \\
Fishing & 1.79 & 0.42 & 6.0 & 4.25 & $<0.001$ & 2.62 & 13.7 \\
\hline
\end{tabular}


Table 3 Species and numbers of sharks found on board arrested fishing vessels

\begin{tabular}{|c|c|c|c|c|}
\hline \multirow[t]{3}{*}{ Shark species } & \multicolumn{2}{|c|}{ Vessel name (arrest date) } & \multicolumn{2}{|c|}{ Mean catch } \\
\hline & FV Greeshma & FV Bosin & Number & Per cent (\%) \\
\hline & $(4 / 12 / 14)$ & $(14 / 12 / 14)$ & & \\
\hline Silvertip & 98 & 28 & 63 & 35 \\
\hline Grey reef & 60 & 4 & 32 & 18 \\
\hline Whitetip reef & & 13 & 7 & 4 \\
\hline Black tip reef & 54 & 6 & 30 & 17 \\
\hline Blacktip & 50 & & 25 & 14 \\
\hline Other sharks & 28 & & 14 & 8 \\
\hline Tiger & 10 & & 5 & 3 \\
\hline Bull & 6 & & 3 & 2 \\
\hline Scalloped hammerhead & 1 & & 1 & 0 \\
\hline Oceanic whitetip & 1 & & 1 & 0 \\
\hline Total & 308 & 51 & 180 & \\
\hline
\end{tabular}

conversion cost, with the government aiming to convert 2000 trawlers to deep sea longlining (https://www.thehi ndu.com/todays-paper/tp-national/tp-tamilnadu/deepsea-fishing-project-receives-good-response/article 195 37620.ece). If successful, and unless properly policed, this policy may lead to an increased number of vessels targeting the BIOT MPA.

The high proportion of reef-associated sharks found in the seized catches of illegal fishing vessels suggests that illegal fishing activities specifically target these species rather than taking them as bycatch. While the exact number of sharks removed during such incursions cannot be known, the mean catches of the nine illegal fishing vessels detained in BIOT during 2014 contained an average of 137 sharks per vessel, suggesting that over 2000 animals may have been removed by the 17 vessels observed during December 2014. This per-vessel estimate is lower than the mean catches of the two Indian-flagged vessels arrested at the time (180 sharks per vessel), so our estimate of per-vessel catch might be considered conservative. We may also have underestimated the total number of vessels involved in the fishing event, given an estimated detection efficiency by the patrol vessel of only $10 \%$ [36]. Regardless of the true total, the sharks removed likely represent a significant proportion of the local population: assuming the tagged sharks are representative of the local untagged animals a simple closed population mark-recapture model would suggest that as much as one-third of the reef sharks could have been removed from the monitored reefs in vicinity of our tagging sites during December 2014. However, since the location and total effort of the fishing activities are unknown, this estimate may represent a very localised impact.

\section{Conclusion}

Given the relatively low fecundity of most reef sharks $[41,42]$, large illegal fishing events, such as described above and suspected to have occurred in December 2014, may have a lasting negative impact on overall reef shark abundance, impacting the effectiveness of MPAs and with implications for ecosystem health. Our data show that fishing can also cause significant losses to acoustic monitoring projects in terms of both potential data and equipment, given that a tag's useful life can be up to 10 years without animal mortality. However, our data suggest that further developments in electronic tagging may offer a means to police and deter illegal fishing in protected areas, by remotely detecting fishing events as they happen, as well as perhaps allowing mortality of species of conservation interest in legal fisheries to be better quantified. Satellite-linked receivers, such as the Vemco VR4 Global, are an existing tool that might be used to remotely monitor presence/absence of tagged animals in real time. Additionally, technologies such as FastLocGPS might be adapted to transmit the locations of sharks as they are removed from the water, using a similar approach to that used with Smart Position and Temperature (SPOT) tags. Along with satellite monitoring of vessel activity [43], such remote fishing detection techniques could be used in large remote marine protected areas to complement other enforcement methods, and to better focus resources. By improving detection efficiency by enforcement assets, electronic tagging and complementary technologies offer a means to reduce the currently high cost of effectively enforcing large marine protected areas [44], helping them to achieve their conservation goals. 


\section{Methods}

Data were collected as part of an ongoing acoustic telemetry project in the BIOT MPA (Fig. 3). The project commenced in February 2013 with the deployment of an array of 30 acoustic receivers (Vemco Ltd. Halifax, Canada) and was expanded in April 2014 to 48 receiver elements (Fig. 3). The principal species monitored are determined by availability when shark fishing in the region and to date have been primarily grey reef (Carcharhinus amblyrhynchos) and silvertip sharks (Carcharhinus albimarginatus). Sixty-six sharks were tagged in February and March 2013 (38 grey reef and 28 silvertip sharks) and a further 29 in March 2014 (9 grey reef and 20 silvertip sharks). Grey reef sharks ranged in total length from 75 to $140 \mathrm{~cm}$, and silvertip sharks from 83 to $180 \mathrm{~cm}$. Sharks in the first year were primarily tagged externally using a dart and leader system; from April 2014 all sharks were tagged internally. Receivers were serviced and detection data downloaded annually at the same time of year (March-May) and were last downloaded in March 2018.

Tag IDs in the detection data were matched to metadata for tagged animals (species, sex, length), and time series of the daily detections of each tag were visualised in an abacus plot. Potential lost tags were identified as any that were detected post-tagging but which ceased to be detected before April 2015 (i.e. have remained undetected for at least 3 years). We calculated mean daily and monthly loss rates and 95\% confidence intervals for the first and second years of the project, up until the suspected fishing event in December 2014 (March 2013-March 2014 and April 2014-December 2015, respectively) and also for the total period from February 2013 to December 2014.

We used a Cox proportional hazards analysis to examine the influence of species and the presence of fishing vessels on the survivorship of individual sharks. Survival time was taken as the time from tagging to last detection, and sharks whose last detection data fell within 3 years of the end of the data time series were censored. Thus 'mortality' was coded as 1 for all sharks which had not been observed for 3 or more years as at March 2018, and 0 otherwise. Fishing vessel presence was 1 if at least one fishing vessel had been sighted or arrested up to 2 days after a shark's last detection data, and 0 otherwise. Kaplan-Meier curves were plotted separately for survival models with species (grey reef shark-GRS or silvertip shark-STS) and fishing presence as covariates. A Cox proportional hazard model was used to calculate hazard rates for both species and fishing vessel in a combined model.

Data on illegal fishing activity were obtained from reports made by the UK representatives to the Indian Ocean Tuna Commission [30]. Dates, locations and catch details, where available, were extracted for all vessels sighted during 2014. The distribution of vessel sightings and tag losses per month from April to December 2014 were plotted and visually compared. The mean catch (total and by species) and confidence intervals were calculated from the catches found on all vessels arrested in 2014. The mean catch per vessel was multiplied by the total number of vessels sighted in December 2014 to infer the potential total shark catch for the suspected illegal fishing event. Assuming a closed population and that tagged animals were no different than their untagged conspecifics (except for the presence of a tag), we used a simple Lincoln-Peterson index [45] to broadly estimate the potential share of the local shark population removed by the fishing event.

Meteorological data (wind speed and wave height) were obtained from the European Centre for MediumRange Weather Forecasts ERA-Interim reanalysed data set (https://www.ecmwf.int/en/forecasts/datasets/archi ve-datasets/reanalysis-datasets/era-interim). Data were extracted for the period June 2014 to June 2015 for the northern part of BIOT $\left(-6.5\right.$ to $\left.-4.5^{\circ} \mathrm{S} ; 71.5-72.5^{\circ} \mathrm{E}\right)$ and averaged for each date. Data on the average port cost of marine diesel oil in US dollars per metric tonne were downloaded from Bunker Index (http://www.bunkerinde x.com/prices/bixfree.php?priceindex_id=4). Prices were converted to US\$ per litre assuming an average density of $0.890 \mathrm{~kg} / \mathrm{m}^{3}$ (https://www.exxonmobil.com/english-GQ/ Commercial-Fuel/pds/GLXXExxonMobil-Marine-Disti llate-Fuel). Trends in both meteorological and fuel price data were smoothed using a seven-day rolling mean and plotted against time.

\section{Additional file}

Additional file 1. Supplementary Table S1 and Table S2; supplementary Figures S1-S3

\section{Authors' contributions}

DT, AC, TC, DC and JD collected the field data. DT and AC conceived of the manuscript. DT analysed the data and drafted the manuscript, with input from all co-authors. All authors read and approved the final manuscript.

\section{Author details}

${ }^{1}$ Oceans Institute: Centre for Marine Futures, University of Western Australia, 35 Stirling Highway, Crawley, Perth, WA 6009, Australia. ${ }^{2}$ School of Marine Science and Policy, University of Delaware, Lewes, DE 19958, USA. ${ }^{3}$ Hopkins Marine Station of Stanford University, Pacific Grove, CA 93950, USA. ${ }^{4}$ Institute of Zoology, Zoological Society of London, Regent's Park, London NW1 4RY, UK.

\section{Acknowledgements}

The authors would like to acknowledge the ongoing support of the Bertarelli Foundation, as well as the UK Foreign and Commonwealth Office, of their projects in the BIOT MPA 


\section{Competing interests}

The authors declare that they have no competing interests.

\section{Availability of data and materials}

Data used for the analyses described in the manuscript are available upon request from the authors.

\section{Ethics approval}

Animal handling procedures were approved by the Stanford University Administrative Panel on Laboratory Animal Care under permit APLAC-10765, held by Hopkins Marine Station's Block Laboratory.

\section{Funding}

Fieldwork was funded through a grant to B.B. from the Berteralli Foundation, and supported with in-kind donations of vessel time from the Foundation. DT was supported by an Australian Postgraduate Award while completing a Ph.D. at the University of Western Australia.

\section{Publisher's Note}

Springer Nature remains neutral with regard to jurisdictional claims in published maps and institutional affiliations.

Received: 15 July 2018 Accepted: 2 January 2019

Published online: 11 January 2019

\section{References}

1. Vianna G, Meekan MG, Meeuwig JJ, Speed CW. Environmental influences on patterns of vertical movement and site fidelity of grey reef sharks (Carcharhinus amblyrhynchos) at aggregation sites. Plos ONE. 2013;8:e60331.

2. Freitas C, Olsen EM, Knutsen H, Albretsen J, Moland E. Temperatureassociated habitat selection in a cold-water marine fish. J Anim Ecol. 2016;85(3):628-37.

3. Carey FG, Kanwisher JW, Brazier O, Gabrielson G, Casey JG, Harold L, Pratt SJS. Temperature and activities of a White Shark, Carcharodon carcharias. Copeia Am Soc Ichthyol Herpetol (ASIH). 1982;1982(2):254-60.

4. Campbell HA, Watts ME, Sullivan S, Read MA, Choukroun S, Irwin SR, et al. Estuarine crocodiles ride surface currents to facilitate long-distance travel. J Anim Ecol. 2010;79(5):955-64.

5. Burnett NJ, Hinch SG, Braun DC, Casselman MT, Middleton CT, Wilson $\mathrm{SM}$, et al. Burst swimming in areas of high flow: delayed consequences of anaerobiosis in wild adult sockeye salmon. Physiol Biochem Zool Ecol Evolut Approaches. 2014;87(5):587-98.

6. Kessel ST, Cooke SJ, Heupel MR, Hussey NE, Simpfendorfer CA, Vagle $S$, et al. A review of detection range testing in aquatic passive acoustic telemetry studies. Rev Fish Biol Fish. 2013;24(1):199-218.

7. Halfyard EA, Webber D, Del Papa J, Leadley T, Kessel ST, Colborne SF, et al. Evaluation of an acoustic telemetry transmitter designed to identify predation events. Methods Ecol Evolut. 2017;54(2):287.

8. Rechisky EL, Welch DW. Surgical implantation of acoustic tags: influence of tag loss and tag-induced mortality on free-ranging and hatchery-held spring Chinook salmon (O. tshawytscha) smolts. In: Wolf KS, O'Neal JS (eds) PNAMP special publication: tagging, telemetry and marking measures for monitoring fish populations - a compendium of new and recent science for use in informing technique and decision modalities 2010-002, pp. 69-94.

9. Papastamatiou YP, Meyer CG, Carvalho F, Dale JJ, Hutchinson MR, Holland KN. Telemetry and random-walk models reveal complex patterns of partial migration in a large marine predator. Ecology. 2013;94(11):2595-606.

10. Espinoza M, Heupel MR, Tobin AJ, Simpfendorfer CA. Residency patterns and movements of grey reef sharks (Carcharhinus amblyrhynchos) in semi-isolated coral reef habitats. Mar Biol. 2015;162:343-58.

11. Chapple TK, Chambert T, Kanive PE, Jorgensen SJ, Rotella JJ, Anderson SD, et al. A novel application of multi-event modeling to estimate class segregation in a highly migratory oceanic vertebrate. Ecology. 2016;97(12):3494-502

12. Sandstrom PT, Ammann AJ, Michel C, Singer G. Growth, survival, and tag retention of steelhead trout (Oncorhynchus mykiss) and its application to survival estimates. Environ Biol Fish. 2013;96:145-64.
13. Jepsen N, Thorstad EB, Havn T, Lucas MC. The use of external electronic tags on fish: an evaluation of tag retention and tagging effects. Anim Biotelem. 2015:3(1):49.

14. Heupel MR, Semmens JM, Hobday AJ. Automated acoustic tracking of aquatic animals: scales, design and deployment of listening station arrays. Mar Freshw Res. 2006;57(1):1.

15. Espinoza M, Lédée EJl, Simpfendorfer CA, Tobin AJ, Heupel MR. Contrasting movements and connectivity of reef-associated sharks using acoustic telemetry: implications for management. Ecol Appl. 2015;25(8):2101-18. https://doi.org/10.1890/14-2293.1.

16. Speed CW, Meekan MG, Field IC, McMahon CR, Harcourt RG, Stevens JD, et al. Reef shark movements relative to a coastal marine protected area. Reg Stud Mar Sci. 2016;3:58-66.

17. Vianna GMS, Meekan MG, Bornovski TH, Meeuwig JJ. Acoustic telemetry validates a citizen science approach for monitoring sharks on coral reefs. PLoS ONE. 2014;9(4):e95565.

18. McCauley DJ, Young HS, Dunbar RB, Estes JA, Semmens BX, Micheli F. Assessing the effects of large mobile predators on ecosystem connectivity. Ecol Appl. 2012;22(6):1711-7.

19. Barnett A, Abrantes KG, Seymour J, Fitzpatrick R. Residency and spatial use by reef sharks of an isolated seamount and its implications for conservation. Plos ONE. 2012;7(5):e36574

20. Chin A, Tobin AJ, Heupel MR, Simpfendorfer CA. Population structure and residency patterns of the blacktip reef shark Carcharhinus melanopterus in turbid coastal environments. J Fish Biol. 2013;82(4):1192-210.

21. Heupel MR, Simpfendorfer CA. Importance of environmental and biological drivers in the presence and space use of a reef-associated shark. Mar Ecol Prog Ser. 2014;496:47-57

22. Espinoza M, Heupel MR, Tobin AJ, Simpfendorfer CA. Movement patterns of silvertip sharks (Carcharhinus albimarginatus) on coral reefs. Coral Reefs. 2015:34(3):1-15.

23. White TD, Carlisle AB, Kroodsma DA, Block BA, Casagrandi R, De Leo GA, et al. Assessing the effectiveness of a large marine protected area for reef shark conservation. Biol Conserv. 2017;207:64-71.

24. Dent F, Clarke S. State of the global market for shark products. FAO Fisheries and Aquaculture Technical Paper. 2015.

25. Kizhakudan SJ, Zacharia PU, Thomas S. Guidance on national plan of action for sharks in India. CMFRI Marine Fisheries Research Institute. 2015.

26. Meekan M, Cappo M, Carleton J, Marriott RR. Surveys of shark and fin-fish abundance on reefs within the MOU74 Box and Rowleys Shoals using baited remote underwater video systems. Prepared for the Australian Government Department of the Environment and Heritage. 2006.

27. Clua E, Vignaud T. Possible collapse of reef shark populations in remote coral reef ecosystems in the Coral Sea (Western Pacific). Cybium (Rev Eur Ichtyol). 2016;40(1):51-9.

28. Vianna GMS, Meekan MG, Ruppert JLW, Bornovski TH, Meeuwig JJ. Indicators of fishing mortality on reef-shark populations in the world's first shark sanctuary: the need for surveillance and enforcement. Coral Reefs. 2016:35:973-7.

29. Carr LA, Stier AC, Fietz K, Montero I, Gallagher AJ, Bruno JF. Illegal shark fishing in the Galápagos Marine Reserve. Mar Policy. 2013;39:317-21.

30. IOTC. IUU Provisional List For 2015 [Internet]. IOTC. 2015. http://iotc.org/ sites/default/files/documents/2015/04/AllEF_20150413.pdf. Accessed: 14 Mar 2016.

31. Barnett A, Abrantes KG, Stevens JD, Bruce BD, Semmens JM. Fine-scale movements of the Broadnose Sevengill shark and its main prey, the Gummy shark. Plos ONE. 2010;5(12):e15464.

32. Field IC, Meekan MG, Speed CW, White W, Bradshaw CJA. Quantifying movement patterns for shark conservation at remote coral atolls in the Indian Ocean. Coral Reefs. 2010;30(1):61-71.

33. Filous A, Friedlander AM, Wolfe B, Stamoulis K, Scherrer S, Wong A, et al. Movement patterns of reef predators in a small isolated marine protected area with implications for resource management. Mar Biol. 2017;164(1):2.

34. Heupel MR, Simpfendorfer CA, Hueter RE. Running before the storm: blacktip sharks respond to falling barometric pressure associated with Tropical Storm Gabrielle. J Fish Biol. 2003;63(5):1357-63.

35. Pyle P, Schramm MJ, Keiper C, Anderson SD. Predation on a white shark (Carcharodon carcharias) by a killer whale (Orcinus orca) and a possible case of competitive displacement. Mar Mamm Sci. 1999;15:563-8.

36. Price ARG, Harris A, Mcgowan A, Venkatachalam AJ, Sheppard CRC. Chagos feels the pinch: assessment of holothurian (sea 
cucumber) abundance, illegal harvesting and conservation prospects in British Indian Ocean Territory. Aquat Conserv Mar Freshw Ecosyst. 2008;20:117-26.

37. Mourier J, Planes S, Buray N. Trophic interactions at the top of the coral reef food chain. Coral Reefs. 2012;32(1):285.

38. Cortés E. Standardized diet compositions and trophic levels of sharks. ICES J Mar Sci. 1999;56(5):707-17.

39. Martin SM, Moir-Clark J, Pearce J, Mees CC. Catch and bycatch composition of illegal fishing in the British Indian Ocean Territory (BIOT) IOTC2013-WPEB09-46 Rev_1 [Internet]. Indian Ocean Tuna Commission WPEB 9. 2013 [cited 2013 Dec 5]. http://www.iotc.org/files/proceedings/2013/ wpeb/IOTC-2013-WPEB09-46\%20Rev_1.pdf.

40. Graham NAJ, Spalding MD, Sheppard CRC. Reef shark declines in remote atolls highlight the need for multi-faceted conservation action. Aquatic Conserv Mar Freshw Ecosyst. 2010;20(5):543-8.
41. Smith SE, Au DW, Show C. Intrinsic rebound potentials of 26 species of Pacific sharks. Mar Freshw Res. 1998;49(7):663-78.

42. Hisano M, Connolly SR, Robbins WD. Population growth rates of reef sharks with and without fishing on the Great Barrier Reef: robust estimation with multiple models. PloS ONE. 2011;6(9):25028.

43. Kroodsma DA, Mayorga J, Hochberg T, Miller NA, Boerder K, Ferretti F, et al. Tracking the global footprint of fisheries. Science. 2018;359(6378):904-8.

44. McCrea-Strub A, Zeller D, Rashid Sumaila U, Nelson J, Balmford A, Pauly D. Understanding the cost of establishing marine protected areas. Mar Policy. 2011;35(1):1-9.

45. Lincoln FC. Calculating waterfowl abundance on the basis of banding returns. Washington, DC: US Department of Agriculture; 1930. p. 1.
Ready to submit your research? Choose BMC and benefit from:

- fast, convenient online submission

- thorough peer review by experienced researchers in your field

- rapid publication on acceptance

- support for research data, including large and complex data types

- gold Open Access which fosters wider collaboration and increased citations

- maximum visibility for your research: over 100M website views per year

At BMC, research is always in progress.

Learn more biomedcentral.com/submissions 